\title{
Historiografía urológica
}

\author{
M. Pérez Albacete \\ Servicio de Urología. Hospital Universitario "Virgen de la Arrixaca". El Palmar (Murcia) \\ Actas Urol Esp 2005; 29 (1): 1-4 \\ La tarea histórica consiste nada menos que en remontar \\ ante nuestros ojos y ante nuestra mente una figura, una \\ institución o un periodo del pasado que a través del \\ recuerdo se hace presente en nuestra vida.
}

Ortega y Gasset

$\mathrm{L}$ a historiografía o arte de escribir la historia es una labor propia del historiador profesional, que escudriña el pasado y analiza desde un punto de vista crítico los sucesos, los personajes y sus obras así como la ilación de los hechos para establecer, de esta manera, los pormenores históricos de cada acontecer, labor esta que se evidencia en todas las ramas de la ciencia.

Se han ocupado principalmente de estudiar la evolución que ha tenido la Urología española a lo largo de la historia los profesores Sánchez Grangel, de la Universidad de Salamanca, su discípulo Riera Palmero, de la de Valladolid, y López Piñero, de la de Valencia, quienes, de un modo técnico, han analizado cuanto ha tenido relación con el aparato urinario y han expuesto el desarrollo de nuestra especialidad en numerosos trabajos. A la par aparecen urólogos prácticos, amantes de la historia, que ofrecen el fruto de sus investigaciones para ahondar en nuestro pasado, con lo que lo enriquecen su conocimiento; inicia esta labor el Dr. Suénder (1829-1897) quien, en 1888 y con motivo del tercer centenario de la publicación de la obra de Francisco Díaz (15271590) "Tratado nuevamente impreso de las enfermedades de riñones, vejiga y carnosidades de la verga y uretra", escribe una memoria de 68 páginas titulada "Noticias de las obras del Doctor Francisco Díaz, célebre médico español del siglo XVI", en la cual señala la importancia del autor a los profesionales de la medicina española; otros urólogos reanudan sus estudios sobre la personalidad y la obra del autor del siglo XVI, así el
Dr. Escribano García (1870-1960), en 1938, realiza una importante revisión histórica de los cirujanos españoles del siglo XVI, en la que destaca entre todos la personalidad de Francisco Díaz y lo fundamental de su "Tratado"; continúa ensalzando su figura el Dr. Mollá Rodrigo (1862-1930) cuando, en 1923, prologa la edición del "Tratado" en la "Biblioteca Clásica de la Medicina Española" con un profundo análisis de su contenido; la trascendencia del personaje es tal que se prosigue con su examen hasta nuestros días como, cuando con ocasión del cuarto centenario del fallecimiento de Díaz, el Dr. Maganto Pavón da a la luz, en 1990, su libro «El Dr. Francisco Díaz y su época", obra trascendental sobre su vida en la que identifica el lugar de su nacimiento en Alcalá de Henares, al localizar documentos que así lo prueban, y en la que incluye, también, un completo repaso de su vida además de la relación y análisis de todos sus escritos. Pero sobre todos es el Dr. Puigvert Gorro (1905-1987) quien logra su difusión entre la comunidad urológica internacional al publicar en inglés, en la revista European Urology, en 1978, "Coments on an old book", artículo con el que da a conocer el libro y su autor y que, seguido de una campaña de divulgación en los países de habla inglesa, y consigue que ambos sean considerados, el uno como el primer tratado netamente urológico escrito en el mundo y el otro como "Padre de la Urología".

Varios son los modos y maneras en que la historiografía presenta las posibilidades de estudio: la investigadora, como la forma más pura, es 
aquélla en la que uno se sumerge en la búsqueda del pasado a través de un hilo conductor que puede esclarecer una noticia poco conocida, la secuencia evolutiva de un proceso patológico, una biografía, o cualquier otro tema de interés; las más de las veces puede ser casual el hallazgo de una breve cita o de un dato, en ocasiones unas simples líneas que pongan en alerta sobre la importancia de resaltar o de profundizar en el acontecimiento encontrado; precisa de una amplia heurística, esto es, de recurrir a las fuentes de información y requiere, además, de horas de estudio en bibliotecas, de búsqueda en hemerotecas, de lectura de libros antiguos, de notas en artículos, de análisis de documentos, etc., lo que conlleva, también, recorridos por organismos oficiales, archivos, parroquias, registros etc., que permitan localizar noticias de un personaje, de unos hechos, o de una fecha, que den confirmación fidedigna a lo indagado, que complementen un estudio, que profundicen en un hecho o que llenen un vacío. Esta labor puede parecer tediosa a veces, en ocasiones sin resultado, pero, por encima de todo, causa gran satisfacción y alegría encontrar lo buscado. Como ejemplos de urólogos que recientemente han destacado en esta faceta señalamos a los Drs. Maganto Pavón, que localiza pruebas que avalan el lugar de nacimiento de Francisco Díaz, y Melchor Galán, quien halla un ejemplar de la obra de Julián Gutiérrez de Toledo "De computationem dierum", que se consideraba perdida, en la biblioteca de los HH. Franciscanos de Santiago de Compostela, el único que se conserva en la actualidad en el mundo y que fue la base de su tesis doctoral en el año 2001.

La revisión histórica nos ofrece un repaso o una exposición de acontecimientos, de hechos y de personas ya conocidos que se presentan bajo unas premisas de estudio seleccionadas por el autor, en esta faceta han destacado el Dr. Cifuentes Díaz (1880-1960) con su trabajo "Bosquejo histórico de la Urología en España anterior al siglo XIX", realizado en 1945 como memoria de ingreso en la Real Academia Nacional de Medicina, los del Dr. Inchausti Cordón (19171989) al repasar nuestra historia en su libro "Compendio histórico de la Urología Española y de su Asociación", en 1982, como ponencia al Congreso Nacional de Urología, el Dr. Moya Prats (1910-1982), en su "Boceto bio-bibliográfico para una historia de la Urología española", publicado en 1936, o el Dr. Gausa Rull, en 1971, con su "Pequeña historia sobre la evolución de la Urología en Barcelona", como ejemplos significativos. El papel divulgador de hechos o acontecimientos concretos del pasado lo han ocupado los Drs. Negrete de los Reyes con su artículo "Algunos apuntes acerca del primer congreso de la Sociedad Internacional de Urología", en 1903, Montero Gómez con el trabajo "La fundación de la Asociación Española de Urología", en 1965, y Vela Navarrete con "Urological knowledge in Renaissance Spain" publicado por el Comité de Historia de la Asociación Europea de Urología, en 1996. De igual modo la exposición de los trabajos realizados a lo largo del año en un servicio es una estimable fuente de información sobre el quehacer diario urológico, así hemos podido conocer el tipo de patologías y de pacientes asistidos en el hospital de La Princesa de Madrid, recogidos en 1881 por el Dr. Federico Rubio (1827-1902), por el Dr. Cifuentes Díaz, en varias crónicas periodísticas de 1912, en España Médica, y por el Dr. Cifuentes Delatte en 1951; el Dr. Sánchez Covisa (1879-1944), a su vez, nos desgrana los trabajos de su servicio entre 1933 y 1936, en la publicación Urología Clínica, editada por él.

La investigación biográfica indaga en la vida de un personaje para aproximarnos en su conocimiento, conlleva una exposición apodíctica seguida del análisis de su personalidad, de su obra, de los hechos más relevantes en los que intervino, etc., es la forma a priori más sencilla de la historiografía pero que requiere introducirse en profundidad en la vida del personaje, para poder expresar con competencia su modo de ser, su manera de pensar, su sapiencia, etc.; son numerosos los compañeros médicos que han realizado este tipo de estudios. Otra forma de historiografía es, también, el análisis de las obras publicadas por los autores clásicos es, en el que destacó el Dr. Puigvert Gorro con el estudio de las obras de Francisco Díaz y de Joaquín Albarrán. Nos permiten las memorias conocer de primera mano las secuencias de una vida, como ejemplos 
exponemos las narraciones del Dr. Cifuentes Delatte, quien nos deleita con sus recuerdos de juventud en artículos como "Mi primer congreso", "Mi aprendizaje de la cirugía endoscópica en Estados Unidos en 1946", "La clínica urológica de Von Lichtemberg en Berlín en 1933", en los cuales nos aporta interesantes datos sobre la Urología de esa época y sobre su vida; de igual modo el Dr. Pulido Martín (1878-1970) remitió durante su estancias en el extranjero, en 1903, artículos sobre sus vivencias, "Crónicas desde Viena", publicados en el Siglo Médico y editados en 1906 como libro bajo el título de "Cartas Médicas"; una vez retirado, en 1946, escribió un relato autobiográfico, "Recuerdos de un médico".

Otro papel de la historiografía es el de asignar la primacía de un procedimiento, de una intervención o de un hallazgo, demostrar qué persona fue quien tuvo la ocurrencia, la puso en práctica con éxito y la divulgó en escritos por vez primera; el historiador intenta aclarar la prioridad en la proclamación de la paternidad de ideas o procesos expuestos al unísono por distintos autores, un ejemplo clásico es el del descubridor del tratamiento de las carúnculas en el siglo XVI.

De todas estos diversos modos de expresión, no podemos señalar a ninguno como de mayor trascendencia o importancia, todos ellos evidencian interés, tanto por el contenido como por la forma, por la riqueza de sus descripciones, su sutileza o su agudeza al adentrarse en los hechos; todos ellos, pues, son fundamentales sin que de ninguno pueda prescindir la historiografia.

Llevado por el espíritu vocacional que le despierta la investigación histórica, el Dr. Maganto Pavón presenta a la Asociación Española de Urología la propuesta de formar un grupo dedicado al estudio de nuestra pasado, el presidente Dr. D. Luis Resel acepta de pleno la idea y la instituye como una Oficina de Historia que, con carácter oficial desde 1996, tiene como objetivos aglutinar a los urólogos interesados por la historia y constituir un equipo que trabaje en su repaso; hasta ese momento eran esporádicos los trabajos de historiografía urológicos que, sin embargo, desde la creación de la Oficina se han incrementado notablemente, prueba de todo ello es que comienzan a presentarse en los Congresos Nacionales varias comunicaciones con motivos históricos, cuyo número se mantiene estable a lo largo de los años; coordinado por el Dr. Maganto se realiza y publica una "Historia Biográfica y Bibliográfica de la Urología Española", en el 2000, seguida dos años más tarde de la parte correspondiente al siglo XX, además de que los miembros de la Oficina, al amparo de la misma, han escrito diversos libros sobre episodios urológicos. Otro de sus objetivos es la recuperación y edición en facsímiles de obras importantes de nuestra Urología para acercar su conocimiento a todos los profesionales y gracias a esta iniciativa se reprodujo el libro de Julián Gutiérrez de Toledo, de 1498, "Cura de la piedra y dolor de la hijada o y cólica renal", que fue entregado en el Congreso de la Asociación celebrado en Cádiz en el año 1998; al siguiente fue repartido, en el desarrollado en Zaragoza el "Tratado del modo de curar las carnosidades y callos de la vía de la orina", de Miguel de Leriza, impreso en Valencia en 1661; "De potu in lapides preservatione", de Gutierrez de Toledo, publicado en 1499, en Barcelona, fue distribuido en el Congreso de Las Palmas de Gran Canaria en el año 2003; y en este último, en Oviedo, el "Methodus cognoscendi, extirpandique excrescentes in vesicae collo carunculas", de Andrés Laguna, editado en Roma en 1551, en versión bilingüe y traducido al castellano por primera vez. En el 2004 se ha abierto una página en Internet de la Oficina de Historia de la AEU en la que se recogen variados textos de interés histórico urológico para, de este modo, facilitar el acceso a su consulta y conocimiento.

A la par, la revista Archivos Españoles de Urología, editada por el Dr. Pérez Castro Ellendt, crea, en el año 2002, una sección en sus páginas destinadas a la Historia y en la que comienzan a aparecer trabajos sobre temas históricos a los que da un tratamiento preferencial; en el mismo año la publicación Urología Integrada y de Investigación, dirigida por el Dr. Salinas, ofrece, en el mes de abril, bajo la coordinación del Dr. Sánchez de Badajoz, un número monográfico dedicado a la Investigación histórica en Urología en el que se recogen importantes aportaciones al conocimiento retrospectivo de nuestra especialidad. 
En este momento en el que Actas Urológicas Españolas, como órgano representativo de la Asociación Española de Urología, afronta un nuevo cambio, cuando su director, el Dr. Ruiz Cerdá, apuesta por organizar una nueva sección en el seno de la revista bajo el epígrafe de Historia de la Urología, solicitada en varias ocasiones por los miembros de su Oficina de Historia; como actual coordinador de la misma, me congratulo de esta iniciativa, felicito a su director por ello y animo a todos los urólogos a que se esfuercen, escriban y remitan sus originales a la publicación dado el creciente interés despertado por los estudios históricos, para, de este modo, engrandecer la Urología hispana con el reconocimiento y el recuerdo de su pasado.

Mariano Pérez Albacete

\section{Bibliografia citada:}

"Cómo operan nuestros cirujanos, el Dr. D. Pedro Cifuentes", (1912): España Médica.

Cifuentes Díaz, P. (1945): «Bosquejo histórico de la Urología en España anterior al siglo XIX", Real Academia Nacional de Medicina, Madrid.

Cifuentes Delatte, L. ( 1985): "Mi primer congreso", Actas Urol Esp Núm. Extra L aniversario AEU.

Cifuentes Delatte, L. (1993): "Mi aprendizaje en la cirugia endoscópica (Estados Unidos, 1946)», Arch Esp Uro 46 (3): 167-180.

Cifuentes Delatte, L. (1995): «La clínica urológica de Von Lichtemberg en Berlín (1933)», Arch Esp Uro 48 (2): 105-112.

Escribano García, V. (1938): "La cirugía y los cirujanos españoles del siglo XVI. El Dr. Francisco Díaz", Imprenta H. Paulino Travesert, Granada.
Gausa Rull, P. (1971): "Pequeña historia sobre la evolución de la Urología en Barcelona", Llibre d’Actas I Congrés Internacional d’História de la Medicina Catalana", II: 312-317. Montpellier.

Inchausti Cordón, J. L. (1982): "Compendio histórico de la Urología Española y de su Asociación", Ponencia al IV Congreso Iberoamericano de Urología Acapulco, Méjico.

Maganto Pavón, E. (1990): «El Dr. Francisco Díaz y su época", Edit. E. Fabregat, Barcelona.

Mollá Rodrigo, R. (1923): «El Dr. Francisco Díaz, estudio preliminar acerca del autor y sus obras", “Biblioteca Clásica de la Medicina Española”, Madrid.

Montero Gómez, J. (1965): «Fundación de la Asociación Española de Urología", Actas II Congreso de Historia de la Medicina, II: 231-233, Salamanca.

Moya Prats, A. (1936): "Boceto bio-bibliográfico para una historia de la Urología española", Trabajos de la Cátedra de Historia crítica de la Medicina, VII: 83-98, Madrid.

Melchor Galán, J. A. (2002): «Estudio crítico y analítico de la obra urológica de Julián Gutiérrez de Toledo", Tesis doctoral, Madrid.

Negrete De Los Reyes, C. (1908): "Algunos apuntes acerca del primer congreso de la Sociedad Internacional de Urología", Rev. Ibero americana de Ciencias Médicas, Madrid.

Puigvert Gorro, A. (1958): "Comentarios al libro "Medicine operatoire des voies urinaires" de Albarrán", Arch Esp Uro XIV (3): 169-186.

Puigvert Gorro, A. (1978): "Coments on an old book", European Urology.

Pulido Martín A (1906): "Cartas médicas», impr. E. Teodoro, Madrid.

Pulido Martín, A. (1965) "Recuerdos de un médico», imp. J. Cosano,. Madrid.

Suénder, Enrique. (1888): «Noticias de las obras del Doctor Francisco Díaz, célebre médico español del siglo XVI», Madrid.

Vela Navarrete, R. (1996): "Urological knowledge in Renaissance Spain", en De Historia Urologicae Europeae, Vol. II: 139-158. 